\title{
Stratospheric Balloon Measurements of Sferics in Brazil
}

\author{
M.M.F. Saba \\ O. Pinto Jr. \\ I.R.C.A. Pinto \\ R.B.B. Gin \\ O. Mendes Jr.
}

Instituto Nacional de Pesquisas Espaciais - INPE

\begin{abstract}
Measurements of sferics were obtained during two balloon flights launched from Cachoeira Paulista, Brazil, on 26 January 1994 and 23 March 1995 carrying double-probe electric field detectors. The results are discussed in terms of the polarity of the associated lightning flashes and the relationship between the sferic amplitude and the sferic decay time constant. Sferic signatures of one negative flash and two large positive flashes in the quasi-DC and VLF electric field data, obtained in 1995, are presented. From the data obtained in 1994 associated with negatives flashes, a linear relationship between the amplitude and the decay time constant of sferics was found.
\end{abstract}

\section{INTRODUCTION}

Sferic signatures at balloon altitudes have been measured for several authors (e.g. Holzworth and Chiu, 1982; Pinto et al., 1992). The main features of a sferic is a rapid increase followed by a tail, lasting for less than 10 seconds. The sferic tail has a time constant different of the local relaxation time, indicating that it is influenced by processes inside the thunderstorm. In general, the direction of the electric field associated with the sferic is used to determine the polarity of the lightning flash. Upward field is related to negative flashes and downward field to positive or intracloud flashes.

In this paper we present measurements of sferics obtained during two balloon flights launched from Cachoeira Paulista, Brazil (22 $44^{\prime}$ S, $\left.44^{\circ} 56^{\prime} \mathrm{W}\right)$, on 26 January 1994 and 23 March 1995 . We discuss the above criteria for identification of lightning polarity and present data showing a linear relationship between the amplitude and the decay time constant of sferics.

\section{RESULTS}

Figure 1 shows three sferics obtained in 1995 associated with an isolated thunderstorm. The data are shown for quasi-Dc electric field and VLF $(5-200 \mathrm{kHz})$ electric field. The data sample rate is $\mathbf{5 0}$ milliseconds. The first sferic (N1) was found to be associated with a negative flash and the others (P1, P2) with positive flashes.

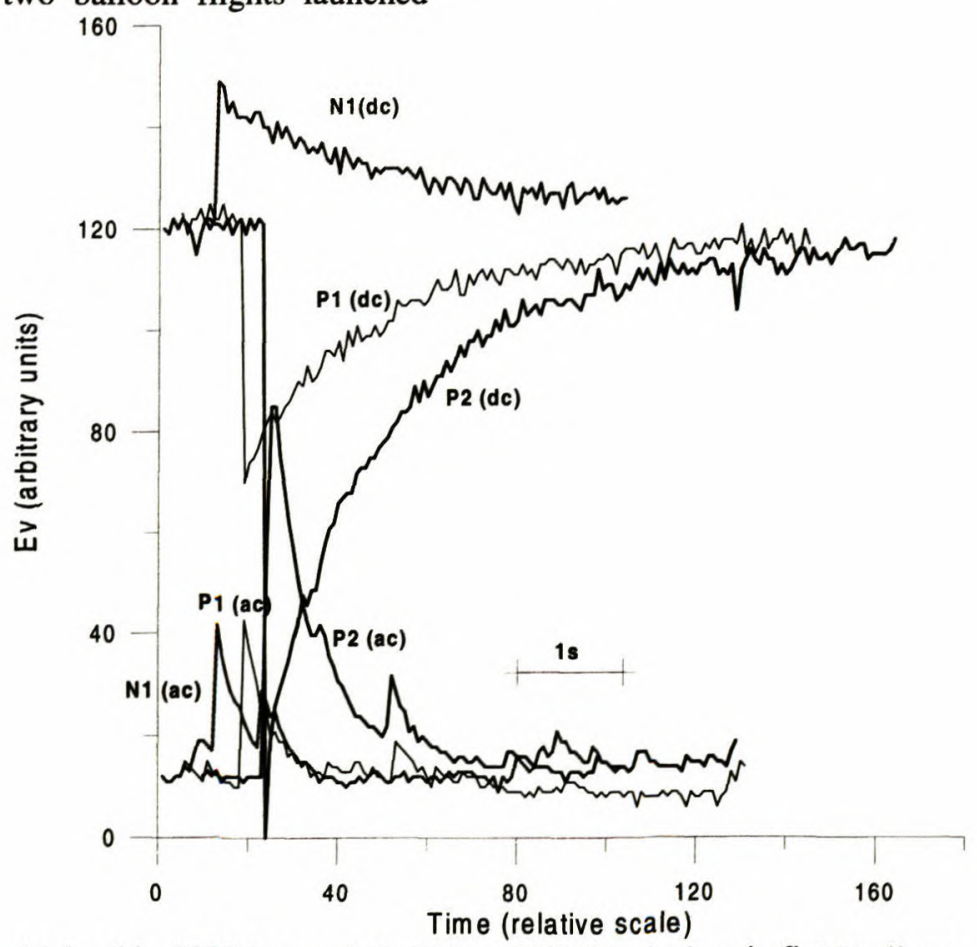

Fig. 1 - Sferics obtained in 1995 in quasi-dc (dc) and VLF (ac) electric field balloon measurements. 
The identification of $\mathrm{P} 1$ and $\mathrm{P} 2$ in figure 1 as positive flashes was based on two facts: firstly, the estimated charge discharged by the flashes associated with the sferics, calculated from the quasi-Dc field assuming the coulomb law; secondly, the ratio between the quasi-Dc and the VLF fields. The charge discharged by the flashes was calculated from the quasi-DC field using the coulomb law, since the time associated with the lightning event is less than the ambient time response. The distance from the payload to the isolated thunderstorm was obtained by the onboard GPS and the location of the thunderstorm was determined from the meteorological radar of Bauru. We have found $16 \pm 10 \mathrm{C}$ and $43 \pm 30 \mathrm{C}$, respectively.

The large uncertainty is associated with the location of the lightning flash with respect to the thunderstorm. This values are larger than the normal values expected from intracloud flashes (Ogawa, 1982), while are of the same order of those associated with positive flashes (Berger, 1975).

The ratio between the peak of the quasi-Dc field and the VLF field was found to be 0.93 for N1, 1.68 for P1 and 1.66 for P2. This values are consistent with the assumption that positive flashes have normally longer trajectories in the atmosphere than negative flashes and, in consequence, a higher component in low frequencies. The opposite should be expected if the flashes were intracloud flashes.

Figure 2 shows the relationship between the amplitude of the sferics associated with negative cloudto-ground flashes and their decay time constants. The data were obtained on 26 January 1994. Figure 2 also shows the results obtained by Burke (1975) for intracloud flashes. The best fit lines for both cases are presented. They indicate that the parameters are very well correlated for cloud-to-grcund flashes, while for intracloud flashes the amplitucle seems to remain almost constant for different values of the decay time constant. Such a different behavior may be associated with the different types of lightning considered in each case. It is worth noting that for large cloud-to-ground flashes the decay time constant can be higher than the relaxation time constant.

\section{CONCLUSIONS}

Sferic data were obtained in Brazil during two balloon flights. The data are discussed and compared with similar data obtained by other authors. The criteria for the identification of two lightning sferic signatures as being due to positive flashes were presented. A linear relationship between the amplitude and the decay time constant for negative lightning sferic signatures was found. The reasons for such a relationship remains to be investigated.

\section{ACKNOWLEDGMENTS.}

The authors would like to thank the Fundação de Amparo à Pesquisa do Estado de São Paulo (F/APSP) for supporting the research through the project 92/4774-2.

\section{REFERENCES}

Berger, K.; Anderson, R.B.; Kroninger, H. Parameters of Lightning Flashes. Electra, 80:23-37, 1975.

Burke, H.K. Large scale atmospheric electric fields: comparisons with balloon data. (Ph.D. Thesis) - Rice University, Houston, Tex., 1975.

Holzworth, R.H.; Chiu, Y. T. Sferics in the stratosphere. In: Volland, H., ed. Handbook of Atmospherics. Florida, CRC, 1982, v.2.

Ogawa, T. The lightning current. In: Volland, H., ed. Handbook of Atmospherics. Florida, CRC, 1982, v.1.

Pinto, I.R.C.A.; Pinto Jr., O.; Gin, R.B.B.; Diniz, J.H.; Carvalho, A.M. A coordinated study of a storm over the South American continent: 2. Lightning- related data, Journal of Geophysical Research, 97(D16):1820518213, 1992.

Volland, H. Atmospheric Electrodynamics. New York, N.Y., Springer Verlag, 1984.

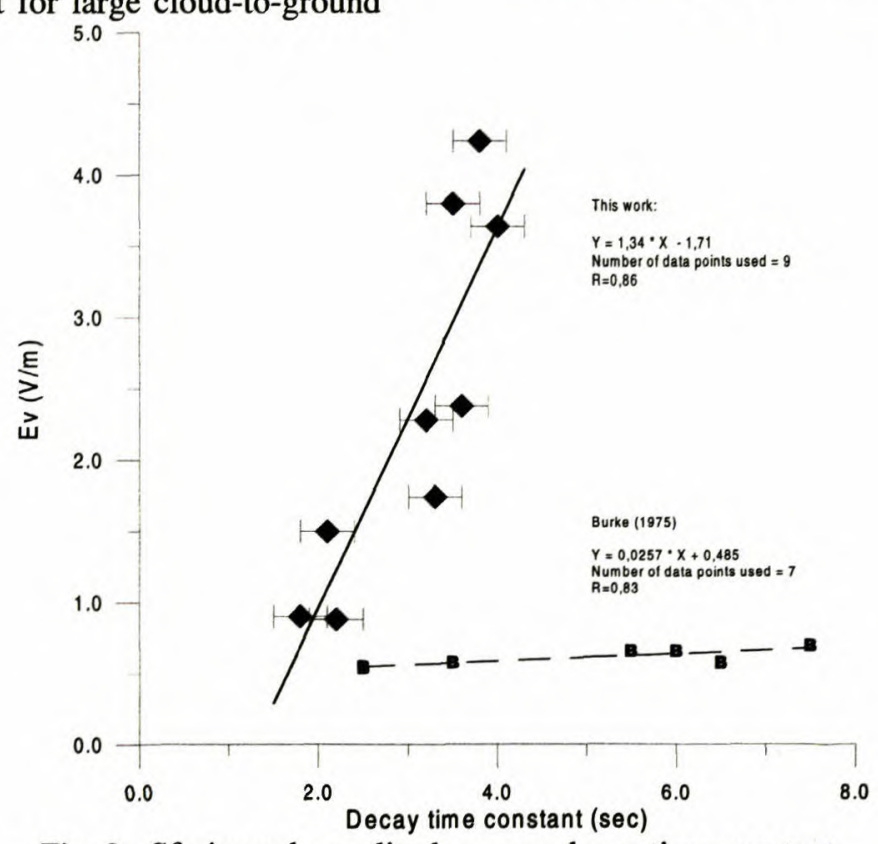

Fig. 2 - Sferic peak amplitude versus decay time constant. 